\title{
El tratamiento de las partes de la oración en el Arte de la lengua española castellana de Gonzalo Correas
}

\author{
Luis Alberto Hernando Cuadrado* \\ Universidad Complutense de Madrid, España
}

\section{INTRODUCCIÓN}

La lengua, para G. Correas, en cuanto "la habla i lenguaxe de qualquiera nazion" ( $A L E C$, fol. $57 \mathrm{r}$. $)^{1}$, no es algo innato, sino adquirido. Es un sistema de expresión y comunicación que se va aprendiendo poco a poco en la infancia oyendo hablar a las personas que nos rodean, cuando se trata de la lengua materna, o mediante el estudio y la comparación con el idioma propio, en el caso de una lengua extranjera. El análisis del mecanismo de una lengua, de las normas o leyes que rigen su funcionamiento, es el objeto del llamado Arte de Gramática. Recordando la definición que M. Capella

Para correspondencia, dirigirse a: Luis Alberto Hernando Cuadrado (lahernando@filol. ucm.es), Departamento de Lengua Española y Teoría de la Literatura y Literatura Comparada, Facultad de Filología, Universidad Complutense de Madrid, Ciudad Universitaria, 28040 MADRID, España.

$1 \quad A L E C=\mathrm{G}$. Correas, Arte de la lengua española castellana. El significado del término nación aquí es el de 'comunidad o grupo étnico, cultural o geográfico'. En este sentido, comenta el autor en otro lugar que nuestra lengua "se llama Castellana, porque se habla i es propia en Castilla, nazion prinzipal i la maior de España, la que está mas en su corazon i zentro, de donde se estiende a las otras provinzias della: i como xeneral a todas se llama también Española" (ALEC, fol. $60 \mathrm{r}$.). 
y San Isidoro habían popularizado en la Europa Occidental -scientia gnara recte scribendi et recte loquendi-, G. Correas indica que "Arte de Gramatica se llama la que trata $\mathrm{i}$ enseña los prezetos i rreglas para entender $\mathrm{i}$ hablar una lengua" ( $A L E C$, fol. 60 r.).

Estas normas, lejos de ser caprichosa o arbitraria invención de los gramáticos, se obtienen a través de "la conformidad i conzierto del hablar natural ò usual de las xentes" ( $A L E C$, fol. 57 r.). Como ya se había observado en la Edad Media, unas son generales, y convienen a todos los idiomas; y otras, particulares, y los singularizan, distinguiéndolos unos de otros. En este sentido, como dice textualmente el autor, la gramática de una lengua "contiene i enseña los prezetos xenerales que convienen à todas lenguas, $\mathrm{i}$ los particulares que pertenezen à sola aquella de que trata" (ALEC, fol. 47 r.). Esto es lo que él mismo hace en el Trilingüe de modo elemental, y con mayor extensión y profundidad en el Arte $^{2}$.

Casi todos los gramáticos de la antigüedad coinciden en definir la gramática como el arte de hablar y escribir correctamente y el de leer e interpretar a los autores, y la dividen en dos partes: una, llamada aurística por Diomedes y metódica por Quintiliano, que fija las reglas del lenguaje, y otra, denominada exegética por Diomedes e histórica por Quintiliano, que se ocupa de la interpretación. Correas, del mismo modo que antes A. de Nebrija y el bachiller Thámara, acepta esta división, pero advierte que en su tiempo los gramáticos se habían desentendido de la interpretación literaria, concentrando su atención en lo puramente gramatical. De esta manera, solo se ocupa de la gramática metódica y doctrinal, adoptando la división tradicional en cuatro secciones o tratados: ortografía, o de litteris; prosodia, o de sillabis; etimología, o de dictionibus; y sintaxis, o de oratione.

A este criterio se ajusta la disposición de los tres trataditos contenidos en el Trilingüe. El Arte grande, como llamaba el humanista extremeño a su Arte de la lengua española castellana, ofrece una estructura análoga, aunque el conjunto está enriquecido con capítulos referentes a otras cuestiones. En esta obra, tras la introducción, en la que expone sus propósitos, se ocupa del origen del castellano; del de la escritura y principio de las letras españolas; del abecé o alfabeto castellano, estudiándolo tanto desde el punto de vista ortográfico como del fonético; de la gramática y su contenido; de las partes de la oración, mezclando observaciones morfológicas, prosódicas, sintácticas y semánticas; de la concordancia y la construcción; de las figuras y vicios

2 En la gramática generativa, dentro del contexto de la lingüística actual, se parte de la hipótesis teórica general de la existencia de universales en el lenguaje, de que en las diversas gramáticas particulares subyace una gramática universal. 
de construcción; de los metaplasmos; de los tropos; y de la superioridad del castellano sobre el latín.

De acuerdo con F. Sánchez de las Brozas, que había afirmado en su Minerva que "oratio siue syntaxis est finis grammaticae" (Sánchez de las Brozas 1995: 9), G. Correas señala que "el fin de la Gramatica es la orazion ò habla conzertada" (ALEC, fol. 58 r.). Aunque, lato sensu, llama oración "à todo lo que se habla i dize en boz ò en escrito" ( $A L E C$, fol. 58 r.), stricto sensu la define como "la rrazon i sentido ò habla conzertada que se haze con nonbre i verbo de un mesmo numero i persona, el nonbre en nominativo i el verbo en cadenzia ò persona finita, no infinitivo, i se adorna con la particula si quiere, i con otros casos destas partes, i con ellas mesmas rrepetidas" ( $A L E C$, fols. 58 r.-58 v.).

G. Correas se adhiere a la teoría de que las partes de la oración en cualquier lengua, como ya advirtiera el Brocense (y anteriormente B. de Busto y C. de Villalón), son tres: nombre, verbo y partícula ${ }^{3}$. Si los gramáticos han admitido más, se debe a que han dividido estos tres géneros en especies y subespecies, en las que "se considera alguna diferenzia, ò propiedad particular" ( $A L E C$, fol. 59 r.), pudiéndose hacer "todas quantas partes quisiesemos" (ALEC, fol. 59 r.), pero "nunca saldrán de ser, o nonbre, o verbo, o partezilla, como se ve

3 F. Sánchez de las Brozas había escrito al respecto: "Nam apud Hebraeos tres sunt partes orationis: nomen, uerbum et dictio consignificans. Arabes quoque has tantum tres orationis partes habent: Pheal, uerbum; ismi, nomen; herph, dictionem. Quas tres partes orationis omnes linguae orientales habent. Rabbinus, ille qui contra Cosdram regem persarum disputat, omnes linguas ab hebraica originem duxisse contendit, et graecam et latinam olim tantum tres orationis partes habuisse. Idem sentit Plutarchus in Quaestionibus Platonis; et diuus Augustinus in Cathegoriis ex Aristotelis sententia tres partes orationis constituit" (1995: 10-10 v.). G. Correas, siguiendo muy de cerca esta explicación, apunta que "está llano i asentado en Hebreo, Caldeo i Aravigo, i en todas las otras lenguas Orientales i de Africa, i todas las del Mundo convienen en esto; i era ansi claro i asentado antiguamente en Griego i Latin como lo rrefiere Iuan Isaak en su Arte Hebrea del otro Rrabino que dize en el Libro que escrivió contra el Rrei Cosdroas, que antes en Griego, i Latin no avia mas de tres partes de orazion. Dixo lo mesmo Varron por sentenzia de Dion, aunque disputa otros numeros, i no se afirma, tocólo Quintiliano; i Plutarco siente que son tres en las Questiones de Platon, i San Agustin por parezer de Aristoteles lo saca, i pone tres en las Categorias, aunque estos autores filosofos se van por la Filosofia conformes en que son tres, no claros en la tercera" (ALEC, fols. 59 r.-59 v.). Después de G. Correas, este sistema tripartito de las partes de la oración con el tiempo encontrará eco en algunos autores, como V. Salvá, que subraya que las partes de la oración son tres, "nombre, verbo y partículas; aunque de ordinario se cuentan nueve, por añadirse el artículo, pronombre y participio, cuyos accidentes son los mismos del nombre; y por especificarse las partículas indeclinables, que son las preposiciones, adverbio, interjección y conjunción" (1988: 137), o H. Paul, que distingue entre formas flexivas (nombre y verbo) y formas no flexivas (partículas) (1898). 
claro" (Trilingüe $\left.e^{4}, 12\right)$. Para distinguir entre las palabras de un idioma cuáles son nombres, cuáles verbos y cuáles partículas, nos da la siguiente regla: "Conozerá el nonbre en que tiene singular i plural, i demas deso en Latín i Griego en que se declina por casos: el verbo en que se conxuga $i$ varia por personas i tienpos de singular i plural en todas las lenguas: i la partícula en que es invariable" (ALEC, fol. 59 v.).

\section{EL NOMBRE}

El nombre es definido por G. Correas, atendiendo a su valor significativo y a sus rasgos formales, como "aquella palavra i boz con que se nonbra cada cosa, i tiene xeneros, articulos, numeros, casos ò diferenzia de casos con preposiziones" ( $A L E C$, fol. 60 v.). De esta manera, en castellano, es nombre toda palabra susceptible de experimentar variación en su terminación para distinguir el plural del singular: casa / casas; verde / verdes; él / ellos; ese / esos; alguno / algunos. Pero hay unidades, como el relativo que o el indefinido alguien, que, perteneciendo a la categoría del nombre por su significación y uso, son invariables desde el punto de vista de la forma.

Basándose en A. de Nebrija, G. Correas reconoce en el nombre seis accidentes: calidad, especie, figura o compostura, género, número y caso ${ }^{5}$. Por la calidad, se distingue "el nonbre xeneral, i comun" (ALEC, fol. 91 r.) (varón, ciudad) del "propio, i particular" (ALEC, fol. 91 r.) (Carlos, Plasencia), así como el adjetivo (blanco) del sustantivo: tierra; por la especie, "el nonbre derivado" (ALEC, fol. 91 r.) (montero) del primitivo o "primoxenito" (ALEC, fol. 92 r.): monte; por la figura, el compuesto (manirroto) del simple: mano; por el género, "aquello porque el macho se distinghe de la henbra, i el neutro de entranbos" (ALEC, fols. 91 v.-

\footnotetext{
4 Trilingüe $=\mathrm{G}$. Correas, Trilingüe de tres artes de las tres lenguas Castellana, Latina $i$ Griega, todas en Romanze.

5 Dionisio de Tracia distingue cinco accidentes: género, especie, figura, número y caso; Donato y Consentio, seis: qualitas, comparatio, genus, numerus, figura y casus; Diomedes y Carisio, cuatro: qualitas, figura, numerus y casus (Diomedes, aunque no lo indica expresamente, en la práctica reconoce también la species); Probo, ocho: qualitas, genus, figura, comparatio, ordo, numerus, casus y accentus, y Prisciano, cinco: species, genus, numerus, figura y casus.
} 
92 r. $)^{6}$; por el número, el plural (mujeres) del singular: mujer; y por el caso, cada una de las situaciones en que puede hallarse el nombre en el esquema sintagmático de todas las demás ${ }^{7}$.

El artículo, al ser "una breve palavra demostrativa, que aconpaña al nonbre i le señala i demuestra singularizado, i declara su xenero" (ALEC, fol. 62 r.), no constituye una parte de la oración especial, dado que en significación, géneros y números tiene calidades de nombre ${ }^{8}$. Así, cuando se dice a un criado dame acá el libro, "se entiende aquel singularmente de que tiene notizia el criado à quien le pido" ( $A L E C$, fol. 61 v.); sin embargo, si se dice dame un libro, "se entiende uno qualquiera sin determinazion zierta: lo mesmo si no se pusiese articulo, ni el indefinido un, una" (ALEC, fol. $61 \mathrm{v}$. $)^{9}$.

El nombre sustantivo y el nombre adjetivo, teniendo en cuenta su modo de significar y su funcionamiento en la oración, se distinguen en que aquel es "el nonbre que sinifica sustanzia corporal, ò espiritual, ò azion, i está i puede estar por si solo en la orazion" (ALEC, fol. 65 v.) (María, ángel,

6 En Dionisio de Tracia, que reconoce en principio tres géneros en los nombres, el masculino, el femenino y el neutro, a los que, haciéndose eco de cierta corriente en vigor en su época, añade el común (de dos) y el epiceno e incluso el omne (común de tres) de los latinos, encontramos ya los seis que se repiten en los gramáticos latinos (Donato, Carisio, Consentio y Prisciano [en Probo son cinco debido a que es excluido el epiceno]), que en A. de Nebrija con el dudoso (ambiguo) llegan a ser siete, tradición que se mantiene en B. Jiménez Patón y G. Correas, que, al suprimir el común de tres, distinguen nuevamente seis. Sin embargo, desde el Anónimo de 1555 la opinión más extendida es que los géneros en castellano son tres: masculino, femenino y neutro. El Brocense, siguiendo las teorías de Platón y Aristóteles, solo acepta el masculino y el femenino (a los que asimila el neutro), los considerados principales por Donato y Prisciano.

7 En castellano, los casos o, mejor, las diferencias de casos, en opinión del autor, son seis: nominativo, genitivo, dativo, acusativo, vocativo y ablativo. En cambio, A. de Nebrija, que rechaza la existencia de declinaciones a la manera latina en nuestra lengua y manifiesta que las diferencias se indican por medio de preposiciones, reconoce cinco (nominativo, genitivo, dativo, acusativo y vocativo) y agrupa los nombres en tres declinaciones: con el singular terminado en $a$ y el plural en as (exceptuándose aquellos cuyo singular finaliza en $a ́, \mathrm{y}$ su plural en áes); con el singular en $o$ y el plural en os; con el singular en $e, i$ o en alguna de las consonantes finales y el plural en $s$ o es (1992: 34 r.-34 v.).

8 E. Alarcos Llorach, desde la perspectiva funcional, explica que "aunque el artículo precede en la secuencia al sustantivo y en la escritura se mantiene separado por un blanco, al revés de los signos que manifiestan el género y el número, que se posponen y se juntan, es también como estos un accidente del sustantivo" (1994: 66).

9 El artículo se usa con los nombres apelativos, y, si acompaña a un sustantivo propio, lo convierte en común: el Juan, los Agustinos. Los infinitivos de los verbos, precedidos de artículo, se hacen nombres: el trabajar hace el valer. Cuando aparecen juntos un sustantivo propio y un adjetivo, el adjetivo lleva siempre el artículo: la dulce Francia. Cuando se encuentran relacionados un sustantivo común y un adjetivo, el artículo va con el sustantivo o con el adjetivo indistintamente, pudiendo decirse la ciudad famosa o la blanca nieve. 
calor), y este, "el nonbre que sinifica propiedad i calidad alguna que se añade al sustantivo [...], i no puede estar en la orazion sin sustantivo, i á de conzertar con él en xenero, numero i caso" (ALEC, fol. 65 v.): el papel blanco; la tinta negra.

El sustantivo y el adjetivo se dividen, a su vez, en varias especies. El sustantivo, en propio, "el nonbre de cada uno, i de cada cosa particularmente puesta” (ALEC, fol. 65 v.) (Blas, Inés, Salamanca), y apelativo o común, "el nonbre general i universal que conprehende debaxo de si muchos particulares" (ALEC, fol. 65 v.): mujer, ciudad, reino. El adjetivo, en "prononbre i rrelativo ${ }^{10}$, en positivo, conparativo, superlativo, i partizipio, en aumentativo, diminutivo ò disminuido, que son los prinzipales, $i$ en otras espezies de menos cuenta que se consideran suxetas à estas" (ALEC, fols. 66 r.-66 v.).

En el subgrupo de las "otras particulares espezies de nonbres" (ALEC, fol. $83 \mathrm{r}$.) el gramático extremeño incluye los derivados, "parte sustantivos, parte adxetivos" ( $A L E C$, fol. 83 r.), que, en realidad, podrían considerarse como adjetivos, ya que "en su sinificazion dizen calidad azesoria, $i$ adherente al suxeto venida de afuera, como si fueran adxetivos claros" (ALEC, fol. 89 r.). En este grupo incluye los patronímicos, que se derivan "del propio del padre para sinificar el hijo de tal padre" (ALEC, fol. 83 r.): González $<$ Gonzalo; los denominativos, que nacen "de otro nonbre" (ALEC, fol. 86 r.): pastelero < pastel; los gentilicios o posesivos, que "sinifican lo mesmo que su primero puesto en xenitivo" (ALEC, fol. 57 r.): español = [hombre] de España; los verbales, que "nazen de verbos conozidamente" (ALEC, fol. $87 \mathrm{v}$.): molienda < moler; los participiales, que "nazen de partizipio, i los destas formas: ada, ida, ado, ido, ador, edor, idor. Si queremos podrán ser formados del partizipio pasivo, i supuesto que todos son verbales, no es nezesario advertir, ni dezir mas de los partizipiales" (ALEC, fol. 89 r.); los adverbiales, que "nazen de adverbios" (ALEC, fol. 89 r. $)^{11}$ : cercano < cerca; los numerales, "los nonbres que sinifican los numeros de contar" (ALEC, fol. 89 r.); y los ordinales, "los nonbres que sinifican la orden de ir unos tras otros" (ALEC, fol. 90 v.).

10 El prononbre i rrelativo comprende todas las especies de pronombres: personales, posesivos, demostrativos, relativos, interrogativos e indefinidos.

11 En todo esto se advierte la influencia de A. de Nebrija en G. Correas, que amplía considerablemente la exposición con ejemplos y nuevas consideraciones. 


\section{EL VERBO}

G. Correas, aunando los criterios semántico y morfológico, en la línea de Dionisio de Tracia, los gramáticos latinos Donato, Carisio, Diomedes y Prisciano, y algunos coetáneos suyos (C. de Villalón, R. Percyvall, J. de Luna, Fray D. de la Encarnación), define el verbo como "aquella palavra que sinifica el hazer i obrar, i dezir las cosas i ser hechas, i obradas, i dezirse: i tiene boz i conxugazion" ( $A L E C$, fol. 98 r.), e igual que A. de Nebrija y los gramáticos grecolatinos, reconoce en esta parte de la oración ocho accidentes: género, especie, figura, tiempo, persona, número, modo y conjugación ( $A L E C$, fol. 121 v.).

Por el género, sostiene nuestro gramático que todos los verbos del castellano son activos, ya que "sinifican hazer alguna cosa" (ALEC, fol. 99 v.), y se subdividen en transitivos, los "activos que pasan en la cosa que dizen, i declaran" (ALEC, fol. 99 v.): leo los libros, oigo las lecciones, pido merced; intransitivos, absolutos o neutros, los que "no pasan en otra cosa, antes en si mesmos se queda, i cunple su sinificazion entera, i llena" ( $A L E C$, fol. 99 v.): duermo, río, vivo; e impersonales, con los que "no se declara quien haze, i pareze que van sin la persona biviente agente que los aconpañe, i determine, ni en el hablar se echa menos, ni se busca" (ALEC, fol. 99 v. $)^{12}$ : llueve, conviene, importa.

Aunque, frente al latín, griego y hebreo, el castellano carece de la voz pasiva, no por ello deja de expresar "todo lo que se ofreze pasivo cunplidamente i con mucha eleganzia i grazia" (ALEC, fol. 108 v.). Según Correas, nuestra lengua suple la pasiva con perífrasis constituidas por la combinación de ser + participio pasado: yo soy amado, tú serías amado, aquél había sido amado; con los pronombres me, te, se, en singular, y nos, $o s$, se, en plural, "xuntandose con las cadenzias ò personas verbales de su numero i persona" (ALEC, fol. 111 r.): consúmome, Sancho se murió, en la plaza se corren toros; con estar + gerundio (forma verbal a la que el autor llama "infinitivo de modo i partizipial" [ALEC, fol. 111 r.]) y los citados

12 Los verbos transitivos pueden comportarse ocasionalmente como intransitivos, "sin pasar à la cosa que declaran" ( $A L E C$, fol. 99 v.) (escribo, como, bebo), y los intransitivos, como transitivos, si se les añade "la cosa que sinifican": vivo vida trabajosa, duermo sueño pesado, ando caminos largos. Del mismo modo, los impersonales se emplean a veces como personales (llovía Dios a cántaros, partí de madrugada y amaneci en la arada, estuve bueno todo el día y anocheci con gran calentura), y los personales, como impersonales, en la tercera persona del plural (allí juegan, aqui leen, en la plaza corren) o en la tercera del singular con la partícula se (ámase, léese, hácese tarde), teniendo en este caso significación "pasiva, ò casi pasiva" (ALEC, fol. $100 \mathrm{v}$.). 
pronombres, pospuestos a estar (estámonos consumiendo) o antepuestos: por la calle se está holgando; o con ir + gerundio y los pronombres mencionados, ligados a ir (voyme mojando) o al gerundio: secándome voy ${ }^{13}$. Como se ve, la pasiva refleja no queda deslindada de los verbos pronominales.

Por la especie, los verbos se dividen en primitivos (amar, temer) y derivados (armar, de armas; sopear, de so y pies), y estos últimos se subdividen en frecuentativos (de beber, beborrear, beberretear, beborretear, beborronear), aumentativos (de negrear, negrecer, ennegrecer), continuativos (amanecer, anochecer, crecer), diminutivos (de comer, comiscar; de oler, oliscar), denominativos (de golpe, golpear; de bobo, bobear, abobar, embobar) y adverbiales: de abajo, abajar; de encima, encimar; de delante, adelantar.

Por la figura, los verbos pueden ser simples (conozco, hago) y compuestos: reconozco, deshago. Dentro del grupo de estos últimos, se distinguen los "venidos del Latin" (ALEC, fol. 120 v.) (convertir, sustentar), "que aca los podemos tener por sinples" (ALEC, fol. $120 \mathrm{v}$.), y los formados en castellano, con prefijo y verbo simple (de batir, abatir; de tornar, entornar), con prefijo y verbo derivado de nombre (de palo, apalear; de ligero, aligerar) y de nombre y verbo: de mano y atar, maniatar; de pierna y quebrar, perniquebrar.

Las personas del discurso, de acuerdo con A. de Nebrija, que sigue, a su vez, a Prisciano, son tres: la primera (yo), "que habla de si" (ALEC, fol. 99 r.); la segunda ( $t u$ ú), "à la qual habla la primera" ( $A L E C$, fol. 99 r.), y la tercera (aquél), "de la qual habla la primera y segunda" ( $A L E C$, fol. 99 r.). En el verbo, las personas se expresan mediante "las cadenzias ò terminaziones que tienen los tienpos, tres en singular, i tres en plural" ( $A L E C$, fol. $A L E C$, fol. 99 r.).

Como la mayoría de los gramáticos latinos (Donato, Carisio, Diomedes, Consentio y Prisciano), A. de Nebrija, C. de Villalón, G. Miranda, R. Percyvall, C. Oudin, y J. A. Zumarán, G. Correas señala explícitamente ${ }^{14}$ que, de la misma manera que en el nombre, los números del verbo son dos, singular y plural. De esta manera, a excepción de los defectivos, los verbos castellanos poseen tres formas en singular y tres en plural, una para cada una de las tres personas del discurso.

13 En ambos casos, el conglomerado constituido por la forma verbal en cuestión y el pronombre átono ocupa el primer lugar dentro del conjunto.

14 Los restantes gramáticos españoles de los siglos XVI y XVII, según se desprende de los paradigmas verbales que proponen, participan de idéntico criterio. 
Los cinco modos que admite A. de Nebrija, siguiendo a Donato y Prisciano (indicativo, subjuntivo, optativo, imperativo e infinitivo), G. Correas los reduce a dos, el demostrativo o indicativo, "que demuestra zierta, i libremente, i es como sustantivo, i esenzial de la orazion" ( $A L E C$, fol. 99 v.), y el subjuntivo, "que habla condizionalmente, $\mathrm{i}$ depende del demostrativo, $\mathrm{i}$ se le xunta como su adxetivo, i no puede estar sin él" ( $A L E C$, fol. 99 v.). El subjuntivo, "sin mudar nada de sus tienpos en letra ò terminazion" ( $A L E C$, fol. 99 v.), presenta distintos matices significativos según "la diversidad i maneras, i propositos de hablar, i las particulas que le modifican" (ALEC, fol. 99 v.), pudiendo ser optativo, potencial, concesivo, deprecativo o "infinito i vago" ( $A L E C$, fol. 99 v.).

Por lo que respecta a los tiempos, G. Correas sigue la tradición de fijar en cinco su número: el presente (llamado también presente en la gramática latina), "que demuestra lo que aora se haze" (ALEC, fol. 98 r.): amo, ame; el pasado no cumplido ni acabado (pretérito imperfecto en la gramática latina), "que muestra lo que se hazia i no se acabó" ( $A L E C$, fol. 98 r.): amaba, amara, amaría, amase; el pasado cumplido y acabado (pretérito perfecto en la gramática latina), "que muestra lo que se hizo, i acabó" (ALEC, fol. 98 r.): amé, he amado, hube amado, haya amado; el pasado más que cumplido (pretérito pluscuamperfecto en la gramática latina), "que muestra que algo se hizo antes que otra cosa, i antes que otro hiziese" ( $A L E C$, fol. 98 r.): había amado, hubiera amado, habría amado, hubiese amado; y el venidero (futuro imperfecto en la gramática latina), "que muestra lo que se á de hazer adelante" (ALEC, fols. 98 r.-98 v. $)^{15}$ : amaré, he de amar, amare, habré amado, hubiere amado.

15 Con el antecedente de A. de Nebrija, G. Correas parece alumbrar la separación entre los tiempos absolutos y los tiempos relativos, pero se aparta de él al considerar como tiempos, y no como modos, el imperativo y el infinitivo. Sobre el primero de ellos afirma que existe un tiempo para mandar "que con palavra Latina le llamamos tienpo inperativo, i en Rromanze le pudieramos llamar tienpo mandador ò mandadero, ò tienpo que manda, i no tiene mas de segunda persona de singular, i segunda plural, que es el numero de uno, i el numero de muchos. En Latin le hazen de modo inperativo sin rrazon" ( $A L E C$, fol. 98 v.). A propósito del segundo, comenta que hay también "un tienpo infinitivo que no tiene mas de una persona vaga i comun à las tres personas bivientes que hablan en anbos numeros, i por todos los tienpos, i casos" ( $A L E C$, fol. 98 v.). Este es el infinitivo de presente: amar. Para expresar tiempo pasado o venidero, explica que suplen esta forma verbal "por rrodeo otros infinitivos" (ALEC, fol. fol. 98 v.): haber amado, haber de amar. Añade que, además, hay un "infinitivo de modo i partizipial" ( $A L E C$, fol. 98 v.), llamado gerundio por los gramáticos latinos (amando), que "declara la manera como algo se haze" ( $A L E C$, fol. 98 v.) -en el paradigma de la conjugación, el autor incluye otro "infinitivo de modo i partizipial" (ALEC, fol. 104 v.) de pasado (habiendo amado) y otro de futuro (habiendo de amar), ambos "por rrodeo" ( $A L E C$, fol. 104 v.)-, y "tres partizipios" (ALEC, fol. 98 v.), correspondientes a los tres tiempos, dos propios (el de presente [amante] y el de pasado: amado) -el participio de 
Las conjugaciones son tres. La primera tiene su infinitivo acabado en -ar, como amar o arar; la segunda, en -er, como tener o comer, y la tercera, en -ir, como consumir o escribir. De esta manera, "los verbos se rreparten en las tres conjugaziones, i unos van por la primera, i otros por la segunda, i otros por la tercera, i ninguno por todas ò por las dos" (ALEC, fol. 98 r.). La segunda y tercera "tienen muchos tienpos semexantes i los demas se diferenzian poco" (ALEC, fol. 98 v.).

\section{LA PARTÍCULA}

La partícula, la tercera parte de la oración, en la que se hallan incluidas la preposición, el adverbio, la conjunción y la interjección, las cuatro partes indeclinables del latín, griego y las otras lenguas, según G. Correas, es la palabra que, al no tener moción de número ni de caso, es formalmente invariable $\mathrm{y}$, desde el punto de vista semántico, denota alguna circunstancia en la oración:

La particula, terzera i ultima parte de la orazion, es aquella palavra que nunca se varia, por numeros ni cadenzias, sino que sienpre se dize de una manera invariable, para sinificar alguna zircunstanzia en la orazion contenida en su sinificazion, i conprehende las quatro partes que en Latin $i$ Griego son indeclinables, como lo son en las otras lenguas, conviene à saber, la preposizion, adverbio, conxunzion, interiezion. I ansi que se divide la particula en estas quatro partes $(A L E C$, fol. 122 v.) 16.

\footnotetext{
presente y el de pasado poseen en el paradigma de la conjugación propuesto por G. Correas sendos suplementos, el que ama y el que amó, respectivamente- y uno, el de venidero, "suplido por rrodeo" (ALEC, fol. 98 v.): el que amaría, el que ha de amar. Al participio que forma parte de los tiempos compuestos ( $h a$ amado), la parte de la oración llamada nombre participial infinito por A. de Nebrija, G. Correas le aplica la denominación de "partizipio ministro" (ALEC, fol. 98 v.) por servir solamente para suplir los tiempos "que se hazen por rrodeo de palavras" ( $A L E C$, fol. 98 v.) y ser "semexante al partizipio de pasado" ( $A L E C$, fol. 98 v.), del que parece tomado "en la boz neutra, comun al numero de uno i al numero de muchos sin mudarse" ( $A L E C$, fol. 98 v.).

16 En el Trilingüe, este autor menciona solamente las lenguas griega y latina como poseedoras de palabras indeclinables, y a la afirmación de que divide la partícula en las cuatro clases de palabras indicadas, añade la puntualización de que a estas las subdivide, a su vez, en sus respectivas especies: " $\mathrm{i}$ conprehende las que en griego i latin son indeclinables: preposizion, adverbio, conxunzion, interxezion, i ansi la dividimos en estas quatro, i estas en otras sus espezies" (Trilingüe, 102).
} 
La preposición, voz que, de acuerdo con su etimología ( $<$ lat. prae + positione), significa "anteposizion" (ALEC, fol. $122 \mathrm{v}$.), dado que "pre es lo mesmo que ante i antes, ò delante" (ALEC, fol. $122 \mathrm{v}$.), es caracterizada por G. Correas, con un doble criterio sintáctico y semántico, como la partícula "que se pone antes del nonbre para determinar la diferenzia de los casos ${ }^{17}$, i sinificar alguna cosa que en ella consiste" (ALEC, fol. 122 v. $)^{18}$. Con el precedente de L. Dolce y P. F. Giambullari, son clasificadas en ziertas y ausolutas (ALEC, fols. 122 v.-123 r.) ${ }^{19}$. Los accidentes de las "verdaderas

17 G. Correas, en el tratamiento del nombre, había hecho notar al lector que en castellano, frente al griego y latín, en realidad no existen casos, expresándose las diferencias significativas de estos por medio de preposiciones: "Los Griegos i Latinos conocen i tienen casos: nosotros no; mas las diferenzias de hablar por ellos, si las conozemos: las quales diferenziamos i hazemos con preposiziones" ( $A L E C$, fol. 62 v.). No obstante, mantiene el término casos y otros de la Gramática latina por no encontrar acuñados otros y con vistas a que puedan ser aprovechados tanto al estudiar nuestra lengua como la latina y griega: "por conpendio y claridad usaremos de casos, i los otros terminos gramaticales de la Arte Latina, porque no ai otros mas acomodados, i nos sirvan aqui, i se lleven sabidos para el Latin i Griego" (ALEC, fols. 62 v.-63 r.). En la edición de 1917 de la Gramática académica se explica que "el castellano tiene una declinación preposicional en compensación de la perdida declinación latina, que las lenguas romances han substituído por las preposiciones y el nombre, así como en latín las desinencias no fueron en su origen otra cosa que partículas que iban detrás de los mismos nombres" (Real Academia Española 1917: 203).

18 La capacidad significativa de la preposición a la que alude G. Correas en la segunda parte de su definición había sido destacada ya en el mundo latino por Donato al concebirla como una "pars orationis quae praeposita aliis partibus orationis significationem earum aut complet aut mutat aut minuit" (Keil [ed.] 1981, IV: 365). El Catedrático de la Universidad de Salamanca se sitúa así en el grupo de tratadistas integrado, entre otros, por el Anónimo de 1555, B. Jiménez Patón, G. Miranda, R. Percyvall, C. Oudin, J. Sanford, H. Doergank, L. Franciosini, B. de San Pedro, D. N. Herranz, J. P. Ballot, A. P. Díaz, L. Pahissa, S. López y Anguta, E. Parral, y M. Fernández y A. Retortillo, que, para conservar los esquemas de la gramática latina, siguen explicando que las preposiciones rigen en nuestra lengua el caso de la palabra a la que preceden. Precisamente por este motivo, F. Sánchez de las Brozas llega a considerar a la preposición en el sistema latino la más importante de las partículas: "Praepositio inter particulas principatum obtinet, propterea quod casus regat, quum caeterae omnes casum regere non possint, etiam si aliter grammaticis uideatur" (1995: 147). Actualmente, la preposición suele ser presentada en los estudios gramaticales como una clase de palabras que se caracteriza formalmente por ser invariable; sintácticamente, por servir de nexo de subordinación entre un elemento inicial (núcleo) y otro terminal (complemento); y semánticamente, por aportar un matiz significativo de intensidad diversa al sintagma o grupo sintagmático que encabeza, de acuerdo con la situación y el contexto. Desde la perspectiva funcional, la preposición actúa como índice funcional, mostrando la relación que contraen determinados funtivos o, en su caso, como transpositor, transponiendo segmentos pertenecientes a una determinada categoría a otra.

19 En la tradición gramatical posterior va a ser frecuente encontrar clasificadas las preposiciones en propias (las que tienen significación solas o en composición con otras palabras) e impropias (las que solo tienen significación uniéndose a otras palabras para formar con ellas una sola dicción; son los prefijos), o, con otros términos, en separables e inseparables o bien en regentes y componentes. 
preposiziones" ( $A L E C$, fol. $130 \mathrm{v}$.) son dos, figura y caso. La figura es "unica i senzilla, i primogenita" ( $A L E C$, fol. 130 v.). Los casos a los que se juntan "son quatro: genitivo, dativo, acusativo, ablativo" ( $A L E C$, fol. 130 v.). A excepción de para, que es "disilaba con el azento en la primera, i le escureze con el de la dizion sighiente, de manera que pareze que no tiene ninguno" (ALEC, fol. 130 v.), las restantes son monosílabas.

El adverbio, como indica su etimología ( $<$ lat. adverbium $<a d+$ verbum $)$, ya que $a d$ en latín "sinifica azerca, i la proximidad i zercania para alguna cosa" ( $A L E C$, fol. 124 r.), es definido por G. Correas como la partícula "que comunmente se xunta al verbo para denotar alguna zircunstanzia ò calidad en él, como el nonbre adxetivo se llega al sustantivo" (ALEC, fol. $124 \mathrm{r}$.), añadiendo a continuación casi con las mismas palabras que A. de Nebrija la puntualización de que "acrezenta ò desminuie, hinche ò mengua, ò muda la sinificazion del verbo" (ALEC, fol. 124 r. $)^{20}$. Los accidentes del adverbio son tres, figura, especie o forma y significación. Las figuras son

20 En el Trilingüe, G. Correas sustituye el término zircunstanzia por azidente y con mayor brevedad que en el Arte explica que el adverbio "es una particula que comunmente se xunta al verbo, para denotar algun azidente i calidad en él, por eso se llama adverbio, el qual acrezienta, mengua, o muda la sinificazion del verbo" (Trilingüe, 103). El adverbio, que aparece tratado por primera vez como parte de la oración en la tercera división de estas realizada por los estoicos al separarlo del nombre común, desde que Dionisio de Tracia lo definiera como la parte indeclinable de la oración que modifica al verbo o lo completa, fue considerado durante mucho tiempo como una palabra asociada exclusivamente al verbo. La definición de Donato ("pars orationis, quae adiecta verbo significationem eius explanat atque implet" (Keil [ed.] 1981, IV: 362) es la fuente directa de la de A. de Nebrija en las Introductiones ("pars orationis indeclinabilis, quae addita verbo significationem eius aut complet, aut mutat, aut minuit" (1533: LV v.), que traduce al castellano en la Gramática: "Adverbio es una de las diez partes de la oración, la cual, añadida al verbo, hinche, o mengua, o muda la significación de aquél" (1992: 42 v.). No obstante, a lo largo de la Edad Media se había ido observando que algunos adverbios, sobre todo los de negación, podían modificar, no solo al verbo, sino también al adjetivo e incluso a otro adverbio. Esta opinión será la que mantendrá J. C. Escalígero, esbozará el Brocense, defenderán los gramáticos filósofos franceses y, una vez introducida en España por G. M. de Jovellanos bajo la influencia de ellos, llegará a convertirse en la más aceptada por los españoles posteriores, entre los que se encuentra A. Bello. En la Gramática académica, en la primera edición (1771) se menciona solamente el verbo; desde la de 1854 hasta la de 1867, el verbo y el adjetivo; en las comprendidas entre 1870 y 1916 , el verbo, el adjetivo, el participio y el adverbio, y desde la edición de 1917 se define como "una parte invariable de la oración, que sirve para calificar o determinar la significación del verbo o la del adjetivo, y a veces la de otro adverbio" (Real Academia Española 1917: 136). En nuestros días, se acepta que la función más importante del adverbio es la de complemento circunstancial. Otras veces, desempeña las de adyacente de un adjetivo o de otro adverbio; las categorialmente neutras de núcleo nominal, atributo del sujeto con un verbo copulativo o semipredicativo y atributo del complemento directo; la de modificador oracional, en sus variantes de indicador de modalidad, comentario oracional y tópico; modificador sintagmático; configurador de un enunciado; o nexiva, como transpositor o como conector discursivo. 
dos, "senzilla" ( $A L E C$, fol. 123 v.) (oi, aier, ende) y "conpuesta" (ALEC, fol. $123 \mathrm{v}$.): antier, dende, así como "los que se hazen por conbinaziones $\mathrm{i}$ rrodeos de palavras" (ALEC, fol. $123 \mathrm{v}$.). Las especies o formas son dos, "primitiva" (ALEC, fol. 123 v.) (oi, mas, luego) y "deriuada" (ALEC, fol. 123 v.): bien < bueno; mal < malo. Las significaciones "son diversas" (ALEC, fol. 123 v.). Los adverbios son "de muchas i variadas maneras" (ALEC, fol. 124 r.). Los simples y primitivos son muy pocos, ya que, por regla general, se suplen "por rrodeos i zircunloquios ò conposizion i xunta de palavras, $\mathrm{i}$ locuciones adverbiales" (ALEC, fol. 124 r.), como por zierto, dondequiera, sin mas ni mas. Al observar que por la vía emprendida la clasificación de los adverbios puede llegar a complicarse, el autor opta por clasificarlos por sus especies, aunque es consciente de que estas son numerosas, "casi tantas como los adverbios" ( $A L E C$, fol. $124 \mathrm{v}$.), y los divide en veintitrés clases $(A L E C \text {, fol. } 124 \mathrm{v} \text {. })^{21}$, mencionando "primero los de lugar, como los mas usuales i necesarios; luego los de tienpo, i negativos i afirmativos; despues los demas" (ALEC, fol. 124 v. ${ }^{22}$.

21 Dionisio de Tracia había reconocido veintiséis; A. de Nebrija, dieciocho; y el Brocense, diecisiete.

22 Atendiendo a su significación, Correas distingue adverbios de lugar (aqui, donde, zerca), de tiempo (oi, antes, quando), de negar (no, tampoco, en ningun modo), de afirmar (si, tanbien, ziertamente), de desear (oxale, o si, plega à Dios), de cantidad (mui, mas, menos), de calidad (bien, mal, buenamente), de llamar (hola, hao, ze), de afincar, apresurar y despertar (ea, aina, sus), de amenazar (para esta, para mi santiguada, à fe à fe), de mostrar (he, cata, mira), de ordenar (primeramente, iten, tras eso), de dudar (acaso, quiza, ara), de preguntar (por que, como, à que fin), de amonestar y manera y modo de hacer (paso, quedo, rrecio), de exceptuar (sino, eszeto que, no estante), de condición (si, con tal que, con condizion que), de semejanza (como, ansi, de manera), de elegir (antes, mas, menos), de concluir (del todo, de todo punto, de rraiz), de jurar (por Dios, pardiez, cuerpo de tal), de disminuir (pasico, en puntillas, à hurtadillas) y de igualdad: rras con rras, al xusto, à la par. Reducidas poco a poco las clases de la categoría del adverbio, en 1769 B. de San Pedro, además de hablar de adverbios simples y compuestos atendiendo a la expresión, distingue siete tipos de acuerdo con su significación. En este contexto, la Real Academia Española, desde la edición de 1771 de la Gramática hasta la de 1962, divide los adverbios, en primer lugar, en simples (cerca) y compuestos: adonde, sabiamente. En la de 1771, en el grupo de los compuestos incluye también, bajo la denominación de modos adverbiales, las combinaciones, en palabras separadas, de preposición + adverbio (desde aqui), las cuales, aunque en la de 1796 se estudian en parágrafo aparte, en la de 1854 vuelven a ser consideradas como compuestos, y en la de 1870, en la que se señala que por su forma los adverbios se dividen en simples y compuestos, ya no se incluyen. Atendiendo a su significación, desde la edición de 1771 se distinguen adverbios de lugar (ahí, aquí, alli), tiempo (hoy, ayer, mañana), modo (bien, mal, así), cantidad (mucho, poco, bastante), comparación (más, menos, peor), orden (primeramente, antes, después), afirmación (sí, ciertamente, verdaderamente), negación (no) y duda (acaso, quizá), y en la de 1917 se excluyen los de comparación. En la actualidad suelen establecerse diferentes clasificaciones de los adverbios según se atienda a su origen (primitivos [cerca] y derivados: fácilmente), estructura (simples [aqui], compuestos [anteayer] y complejos: 


\section{Bajo la influencia de A. de Nebrija, G. Correas apunta que la conjunción} ( $<$ lat. coniuctione) es la partícula "que xunta en uno partes diversas, que es palavras i oraziones" (ALEC, fol. $129 \mathrm{r}$. $)^{23}$. Sus accidentes son dos, figura y significación. Las figuras, a su vez, son, asimismo, dos, "senzilla" (ALEC, fol. $130 \mathrm{v}$.) (ca, o, $i) \mathrm{y}$ "conpuesta" (ALEC, fol. $130 \mathrm{v}$.): porque, por ende. Las significaciones "son diversas" ( $A L E C$, fol. $130 \mathrm{v}$.). Las principales especies de la conjunción, que se llama así "por este xuntar" ( $A L E C$, fol. 129 r.), son las copulativas, disyuntivas, causales o racionales, condicionales y continuativas -de cuyo carácter, como advierte A. de $\mathrm{Nebrija}^{24}$, participan todas por continuar la oración-, y, aunque se podrían añadir otras secundarias, dado que su distinción carece de interés, es preferible dejarlas en el grupo del adverbio (ALEC, fol. 129 r. $)^{25}$.

(a cierra ojos), punto de vista semántico (lugar [ahi], tiempo [hoy], modo [bien], cantidad [más], conformidad o no de lo enunciado respecto a la realidad: afirmación [si], negación [no] y duda: quizá), o al carácter léxico o gramatical de sus unidades (según el cual, siguiendo el paralelismo con los adjetivos, habría que hablar de adverbios del tipo I [ $\mathrm{mal}$ y adverbios del tipo II: alli). No obstante, E. Alarcos Llorach sostiene que, junto a la clasificación semántica, también "se baraja otra que obedece a criterios en parte funcionales" (1994: 130), pero es preferible "atenerse a las relaciones que cada uno contrae dentro de los enunciados, bien en su papel primario de adyacente circunstancial, bien por su combinación con otras unidades en el interior de un grupo nominal unitario" (1994: 130).

23 A. de Nebrija, que, en un pasaje de las Introductiones repite casi literalmente lo expuesto por Donato y Probo ("Pars orationis indeclinabilis, connectens ordinansque sententiam" [1533: LVII]) y en otro lugar de la misma obra, siguiendo a Diógenes Laercio (la palabra indeclinable que une entre sí las diversas partes de la oración [Lallot 1989: 233]) y Prisciano ("Pars orationis indeclinabilis, coniunctiva aliarum partium orationis, quibus consignificat, vim vel ordinationem demonstrans" [Keil (ed.) 1981, III: 93]), indica que la conjunción sirve también para unir partes de la oración ("Coniunctio est quae diuersas partes orationis coniungit" [1533: XIV v.]), en la Gramática fusiona ambos puntos de vista al manifestar que la "conjunción es una de las diez partes de la oración, la cual aiunta i ordena alguna sentencia" (1992: 44 r.) y añadir que "llámase conjunción, por que aiunta entre sí diversas partes de la oración" (1992: 44 r.). Esta postura según la cual la conjunción une palabras con palabras y oraciones con oraciones será la predominante en la tradición gramatical posterior. La que mantienen, por ejemplo, B. de San Pedro, la Gramática de la Real Academia Española o R. Lenz. Aunque ha sido frecuente distinguir entre conjunciones coordinantes y subordinantes, A. Bello reconoce como tales solamente a las primeras. En la Gramática Funcional, de acuerdo con él, a las unidades de aquel tipo se les atribuye el papel de conectores, y a las de este, el de transpositores.

24 A. de Nebrija había citado también cinco clases de conjunciones en español, copulativas ("para aiuntar palabras i sentencias" [1992: 44 r.]), disyuntivas ("para aiuntar las palabras i desaiuntar las sentencias" [1992: 44 r.]), causales ("para dar causa" [1992: 44 r.]), conclusivas ("para concluir" [1992: 44 r.]) y continuativas ("para continuar" [1992: 44 r.]).

25 A continuación, explica G. Correas que las conjunciones copulativas $(e, i$, tan bien, $i$ tanbien, $i$ aun ) "xuntan palavras i sentenzias" (ALEC, fol. 129 r.); las disyuntivas $(o, u, n i)$ "xuntan palavras, i dividen sentenzias" (ALEC, fol. $129 \mathrm{v}$ ); las causales o racionales (ca, que, porque, por ende, por tanto, pues, pues que, ansi que, asi que, ansina, onde, luego, por eso, e por tanto, 
La interjección (< lat. interiectione), según G. Correas, es la partícula "que declara el sentimiento del animo de dolor, ù de alegria, ò admirazion" $(A L E C \text {, fol. } 130 \text { r. })^{26}$. Al ser estos sentimientos constantes entre los seres humanos, "algunas son comunes à todas lenguas" (ALEC, fol. $130 \mathrm{r}$. $)^{27}$. Las clases principales en torno a las cuales se agrupan son de doler (ai, ax, guay), de alegría y placer ( $a$, hala, tararira), de admiración (Xesus, valgate Santa

es à saber, conviene à saber) "dan rrazon i causa" (ALEC, fol. 129 v.); las condicionales (si, como, como si, aunque, dado que, puesto que, puesto caso que, magher, magher que, maghera, pues, pues que, mas, mas si, pero, enpero, antes, siquier, siquiera, ia que, con tal que, si que, besique) "dizen condizion" (ALEC, fol. 129 v.); y las continuativas (mientras, quando, como, con tal, con tal que) "continuan la orazion" (ALEC, fol. 130 r.). En el mundo clásico, Dionisio de Tracia reconoce nueve clases de conjunciones; Donato y Probo, cinco; y Prisciano, diecisiete. En la Edad Media, la clasificación de Donato fue la más seguida. En los siglos XVI y XVII, aunque W. Lily y J. Colet, y Th. Linacre admiten catorce, en los restantes gramáticos varía poco la situación. Después de G. Correas, durante algún tiempo, los autores solían elaborar sus propias listas de conjunciones, llegando a hacerse estas a veces "enojosas e interminables" (Gómez Asencio 1985: 179). Posteriormente, la división más frecuente comprende las nueve clases que se recogen en la Gramática académica, copulativas, disyuntivas, adversativas, condicionales, causales, continuativas, comparativas, finales, ilativas. A. Hernando García-Cervigón, en este sentido, explica que, en la Gramática académica, "las conjunciones, tal y como se comenta desde la edición de 1870, además de denotar una relación de enlace, determinan la naturaleza del mismo. Atendiendo a este criterio, en la de 1771 se distinguen seis clases: copulativas, disyuntivas, adversativas, condicionales, causales y continuativas; en la de 1796 se añaden dos más, las comparativas y las finales, a las que en la de 1854 se suman las ilativas" (2006: 143-144).

26 De la interjección - anota el autor- "se dirán los mesmos azidentes que del adverbio, i conxunzion" ( $A L E C$, fol. 130 v.). La interjección, incluida en el adverbio por Dionisio de Tracia, es la octava parte de la oración para los gramáticos latinos, a excepción de Varrón. A. de Nebrija, que en las Introductiones, siguiendo a Donato, atribuye a la interjección el estatus de parte de la oración, en la Gramática la considera, como los griegos, una modalidad del adverbio. Después de G. Correas ha habido autores, como B. de San Pedro, u obras, como la Gramática de la Real Academia Española, en que la interjección ha sido tratada como una parte de la oración. Por el contrario, otros, como E. Benot, influidos por el Brocense o por los gramáticos racionalistas franceses seguidores suyos, niegan a la interjección su naturaleza de parte de la oración. Algunos tratadistas, como V. Salvá o R. Lenz, en la línea de G. I. Vossius y J. Wilkins, interpretan la interjección como el equivalente de una oración. Hoy se ve claro que la interjección, por un lado, es una clase de palabra autónoma que, de no mediar la transposición metalingüística, no desempeña una función dentro de la estructura oracional y, por otro, que constituye por sí misma un enunciado de modalidad exclamativa, estableciendo a veces relaciones con otras unidades y formando con ellas enunciados complejos. De acuerdo con su función comunicativa, se distinguen tres tipos de interjecciones, onomatopéyicas, apelativas y sintomáticas.

27 En esta afirmación de G. Correas, algunos autores, como A. Ramajo Caño, ven "una ligera huella de Patón" (1987: 209). Sin embargo, tanto en B. Jiménez Patón como en G. Correas lo que se observa es la huella del Brocense. San Isidoro de Sevilla había observado que "quae voces quarumcumque linguarum proprie sunt, nec in aliam linguam facile transferuntur” (1993: 298). R. Almela Pérez, desde la perspectiva actual, matiza que "la interjección es un fenómeno idiomático, una categoría gramatical que, gozando de un estatuto lingüístico general, se realiza o no en las diversas lenguas, y aun en las que se realiza no lo hace de la misma forma" (1985: 56-57). 
Maria, Dios nos defienda), prohibentes (ta, tate, no decir chus ni mus) y onomatopéyicas: ze, $m u$, zis zas ${ }^{28}$.

\section{CONCLUSIÓN}

De todo lo anterior se desprende que el fin de la Gramática para G. Correas, siguiendo a F. Sánchez de las Brozas, es la oración o habla concertada. Esta, a su vez, como ya habían apuntado B. de Busto, C. de Villalón y, sobre todo, el Brocense, consta de tres partes, dos esenciales, el nombre y el verbo, y otra accesoria, la partícula, que comprende la preposición, el adverbio, la conjunción y la interjección, unidades invariables que denotan alguna circunstancia en la oración.

El nombre, atendiendo a sus aspectos significativo y formal, es definido por G. Correas como aquella palabra y voz con que se nombra cada cosa, y tiene géneros, artículos, números, casos o diferencia de casos con preposiciones. Los accidentes del nombre son seis: calidad, especie, figura o compostura, género, número y caso. Por la calidad, se distingue el nombre general y común del propio y particular; por la especie, el derivado del primitivo o primogénito; por la figura, el compuesto del simple; por el género, el macho de la hembra y el neutro de entrambos; por el número, el plural del singular; y por el caso, cada una de las situaciones en que puede hallarse el nombre en el discurso de todas las demás.

Por el accidente de calidad, se diferencia asimismo el nombre adjetivo del nombre sustantivo. El sustantivo es el nombre que significa sustancia corporal o espiritual, o acción, y está y puede estar por sí solo en la oración, y el adjetivo, el nombre que significa propiedad y calidad alguna que se añade al sustantivo, y no puede estar en la oración sin sustantivo, y ha de concertar con él en género, número y caso. El sustantivo y el adjetivo se dividen, a su vez, en varias especies. El sustantivo, en propio y apelativo o común. El adjetivo, en pronombre y relativo, en positivo, comparativo,

28 La clasificación de la interjección realizada por G. Correas es similar a la del Anónimo de 1555 (1977), en la línea de los gramáticos latinos, especialmente Donato, que distingue como matices principales los de alegría, dolor, admiración y miedo: "Significatio interiectionis in quo est? Quia aut laetitiam significamus, ut evax, aut dolorem, ut heu, aut admirationem, ut papae, aut metum, ut attat, et siqua sunt similia" (Keil [ed.] 1981, IV: 366). 
superlativo, y participio, en aumentativo, diminutivo o disminuido, que son los principales. El pronombre y relativo abarca todas las especies de pronombres: personales, posesivos, demostrativos, relativos, interrogativos e indefinidos. Las otras particulares especies de nombres son los derivados, los numerales y los ordinales. Los derivados, sustantivos y adjetivos, en realidad, podrían considerarse como adjetivos, ya que en su significación dicen calidad accesoria y adherente al sujeto venida de afuera, como si fueran adjetivos claros. En este grupo se incluyen los patronímicos, los denominativos, los gentilicios o posesivos, los verbales, los participiales y los adverbiales. Los numerales son los nombres que significan los números de contar, y los ordinales, los nombres que significan el orden de ir unos tras otros.

G. Correas, adoptando un doble punto de vista semántico y morfológico, en la línea de Dionisio de Tracia, los gramáticos latinos Donato, Carisio, Diomedes y Prisciano, y algunos españoles de su época (C. de Villalón, R. Percyvall, J. de Luna, Fray D. de la Encarnación), define el verbo como aquella palabra que significa el hacer y obrar, y decir las cosas y ser hechas, y obradas, y decirse, y tiene voz y conjugación, y del mismo modo que A. de Nebrija y los gramáticos grecolatinos, reconoce en esta parte de la oración ocho accidentes: género, especie, figura, tiempo, persona, número, modo y conjugación.

Por el género, todos los verbos del castellano son activos, ya que significan hacer alguna cosa, y se subdividen en transitivos, intransitivos, absolutos o neutros e impersonales. A pesar de que, frente al latín, griego y hebreo, el castellano carece de la voz pasiva, no por ello deja de expresar dicho contenido, sobre todo con las perífrasis constituidas por la combinación de ser + participio pasado. Por la especie, los verbos se dividen en primitivos y derivados, y estos últimos se subdividen en frecuentativos, aumentativos, continuativos, diminutivos, denominativos y adverbiales. Por la figura, pueden ser simples y compuestos. Dentro del grupo de estos últimos, se distinguen los procedentes del latín y los formados en castellano, con prefijo y verbo simple, con prefijo y verbo derivado de nombre y de nombre y verbo.

Las personas del discurso, de acuerdo con A. de Nebrija, que sigue, a su vez, a Prisciano, son tres: la primera, que habla de sí; la segunda, a la que habla la primera; y la tercera, de la que hablan la primera y la segunda. En el verbo, las personas se expresan mediante las cadencias o terminaciones de los tiempos. Como la mayoría de los gramáticos latinos (Donato, Carisio, Diomedes, Consentio y Prisciano), A. de Nebrija, C. de Villalón, G. Miranda, R. Percyvall, C. Oudin y J. A. Zumarán, G. Correas señala explícitamente que, de la misma manera que en el nombre, los números del verbo son 
dos, singular y plural. Con ello, a excepción de los defectivos, los verbos castellanos poseen tres formas en singular y tres en plural, una para cada una de las personas del discurso.

Los cinco modos admitidos por A. de Nebrija, siguiendo a Donato y Prisciano (indicativo, subjuntivo, optativo, imperativo e infinitivo), son reducidos por Correas a dos, el demostrativo o indicativo, que demuestra cierta y libremente, y es como sustantivo, y esencial de la oración, y el subjuntivo, que habla condicionalmente, y depende del demostrativo, y se le junta como su adjetivo, y no puede estar sin él. El subjuntivo presenta distintos matices significativos, pudiendo ser optativo, potencial, concesivo, deprecativo o infinito y vago. Los tiempos son cinco: el presente, el pasado no cumplido ni acabado (pretérito imperfecto en la gramática latina), el pasado cumplido y acabado (pretérito perfecto en la gramática latina), el pasado más que cumplido (pretérito pluscuamperfecto en la gramática latina) y el venidero (futuro imperfecto en la gramática latina). Las conjugaciones son tres. La primera, cuyo infinitivo acaba en -ar; la segunda, en -er; y la tercera, en -ir.

La partícula se halla integrada por la preposición, el adverbio, la conjunción y la interjección, las cuatro partes indeclinables del latín, griego y las otras lenguas, que denotan alguna circunstancia en la oración. La preposición es definida por el humanista extremeño, sin salirse de los esquemas de la tradición grecolatina, como la partícula que se pone antes del nombre para determinar la diferencia de los casos y significar alguna cosa que en ella consiste. En su clasificación, aspecto al que en dicha tradición se había prestado poca atención, con el precedente de L. Dolce y P. F. Giambullari, reconoce dos tipos, ciertas y absolutas. Sus accidentes son, asimismo, dos, figura (única, sencilla y primogénita) y caso (genitivo, dativo, acusativo, ablativo).

En la línea de Dionisio de Tracia, los gramáticos latinos y A. de Nebrija, el adverbio es concebido por el catedrático de la Universidad de Salamanca como la partícula que comúnmente se junta al verbo para denotar alguna circunstancia o calidad en él. Sus accidentes son tres, figura, especie o forma y significación. Las figuras son dos, sencilla y compuesta. Las especies o formas son, igualmente, dos, primitiva y derivada. Por la significación se distinguen veintitrés clases (Dionisio de Tracia había reconocido veintiséis; A. de Nebrija, dieciocho; y el Brocense, diecisiete).

Como A. de Nebrija, en el contexto general de la época, el gramático sostiene que la conjunción es la partícula que junta en uno partes diversas, que es palabras y oraciones. Sus accidentes son dos, figura y significación. Las figuras también son dos, sencilla y compuesta. Las significaciones son diversas, principalmente copulativas, disyuntivas, causales o racionales, 
condicionales y continuativas. Aunque podrían agregarse otras secundarias, es preferible dejarlas en el grupo del adverbio.

La interjección, según el autor, es la partícula que declara el sentimiento del ánimo de dolor, alegría o admiración. Como estos sentimientos son constantes entre los seres humanos, algunas son comunes a todas lenguas. Las clases principales en torno a las cuales se agrupan, similares a las del Anónimo de 1555, en la línea de los gramáticos latinos, especialmente Donato, son de doler, de alegría y placer, de admiración, prohibentes y onomatopéyicas.

El mérito de G. Correas reside, por un lado, en haber sabido compaginar con maestría la utilización de las fuentes doctrinales (la tradición grecolatina, A. de Nebrija, el Brocense) con sus propios puntos de vista, y, por otro, en mostrar una fina sensibilidad en la observación del uso de la lengua y sus variedades, a lo que debió de coadyuvar sin duda el hecho de haber nacido y pasado probablemente los primeros años de su vida en su pueblo natal y su propio carácter. Algunos de sus puntos de vista se reflejan y desarrollan, si bien, como es lógico, dentro de un contexto diferente, en algunas corrientes de la lingüística moderna, sobre todo en el funcionalismo y la gramática generativa.

\section{REFERENCIAS BIBLIOGRÁFICAS}

Alarcos Llorach, Emilio. 1994. Gramática de la lengua española. Madrid: Real Academia Española, Colección Nebrija y Bello, Espasa Calpe.

Almela Pérez, Ramón. 1985. Apuntes gramaticales sobre la interjección, $2^{\mathrm{a}}$ ed. Universidad de Murcia.

ANÓNIMO DE 1555. 1977. Útil y breve institución para aprender los principios y fundamentos de la lengua Hespañola, Lovaina, En la oficina de B. Gravio, 1555. Edición facsimilar con estudio e índice de A. Roldán. Madrid: CSIC.

Bello, Andrés. 1988. Gramática de la lengua castellana destinada al uso de los americanos. Con las Notas de R. J. Cuervo. Estudio y edición de R. Trujillo. Madrid: Arco/Libros.

Correas, Gonzalo. 1627. Trilingüe de tres artes de las tres lenguas Castellana, Latina $i$ Griega, todas en Romanze. Salamanca: En la oficina de A. Ramírez. -1954. Arte de la lengua española castellana. Edición y prólogo de E. Alarcos García. Madrid: CSIC, Anejo LVI de la RFE. 
Gómez Asencio, José Jesús. 1985. Subclases de palabras en la tradición española (1771-1847). Ediciones Universidad de Salamanca.

Hernando García-Cervigón, Alberto. 2006. "La conjunción en la GRAE (1771-1917)". Anuario de Estudios Filológicos XXIX: 141-156.

Isidoro de Sevilla, Santo. 1993. Etimologías. Edición bilingüe. Texto latino, versión española, notas e índices por J. Oroz Reta y M. A. Marcos Casquero; introducción general por M. C. Díaz y Díaz. Madrid: Biblioteca de Autores Cristianos.

KeIL, Henricus (ED.). 1981. Grammatici Latini. Hildesheim - New York: G. Olms.

Lallot, Jean. 1989. La grammaire de Denys le Thrace. Paris: Éditions du Centre National de la Recherche Scientifique.

Nebrija, Antonio DE. 1533. Introductiones in latinam grammaticen. Compluti: M. de Eguía.

1992. Gramática de la lengua castellana. Edición crítica de A. Quilis. Madrid: Ediciones de Cultura Hispánica.

Paul, Hermann. 1898. Prinzipien der Sprachgeschichte. Halle: Max Niemeyer.

RAmajo CAÑo, ANTONIO. 1987. Las gramáticas de la lengua castellana desde Nebrija a Correas. Ediciones Universidad de Salamanca.

Real Academia Española. 1771. Gramática de la lengua castellana. Madrid: Por D. J. de Ibarra, Impresor de Cámara de S. M.

1796. Gramática de la lengua castellana. Madrid: Por la Viuda de D. Joaquín Ibarra, Impresora de la Real Academia.

1854. Gramática de la lengua castellana. Madrid: En la Imprenta Nacional.

- 1867. Gramática de la lengua castellana. Madrid: Imprenta de M. Ginesta.

1870. Gramática de la lengua castellana. Madrid, Imprenta y estereotipia de M. Rivadeneyra.

1916. Gramática de la lengua castellana. Madrid: Perlado, Páez y Compañía (Sucesores de Hernando), Impresores y Libreros de la Real Academia Española.

1917. Gramática de la lengua castellana. Madrid: Perlado, Páez y Compañía (Sucesores de Hernando), Impresores y Libreros de la Real Academia Española.

1962. Gramática de la lengua española. Nueva edición, reformada, de 1931, y apéndice con las Nuevas Normas de Prosodia y Ortografía declaradas de aplicación preceptiva desde $1^{\circ}$ de enero de 1959. Madrid: Espasa Calpe.

SALVÁ, Vicente. 1988. Gramática de la lengua castellana según ahora se habla. Estudio y edición de M. Lliteras. Madrid: Arco/Libros.

Sánchez de las Brozas, Francisco. 1995. Minerva o De causis linguae latinae. Introducción y edición de E. Sánchez Salor (Libri I, III y IV); edición de C. Chaparro Gómez (Liber II). Cáceres: Institución Cultural "El Brocense", Excma. Diputación Provincial de Cáceres y Universidad de Extremadura. 